\title{
CORRECTION
}

\section{Correction to: A high-quality cucumber genome assembly enhances computational comparative genomics}

\author{
Paweł Osipowski ${ }^{1}$ Magdalena Pawełkowicz ${ }^{1}$ (1) - Michał Wojcieszek ${ }^{1} \cdot$ Agnieszka Skarzyńska $^{1}$. \\ Zbigniew Przybecki ${ }^{1}$. Wojciech Pląder ${ }^{1}$
}

Published online: 10 January 2020

(c) Springer-Verlag GmbH Germany, part of Springer Nature 2020

\section{Correction to: Molecular Genetics and Genomics https://doi.org/10.1007/s00438-019-01614-3}

The authors would like to correct the citation for the North European B10 line B10v1, which is mentioned in the introduction:

Instead of

“...and North European B10 line B10v1 (GenBank: GCA_000224045.1), which we sequenced previously (PCC Genomics http://csgenome.sggw.pl)".
The correct text should read

“... and North European B10 line B10v1 (GenBank: GCA_000224045.1) (Wóycicki et al. 2011)”.

The original article can be found online at https://doi.org/10.1007/ s00438-019-01614-3.

Magdalena Pawełkowicz

magdalena_pawelkowicz@sggw.pl

Wojciech Pląder

wojciech_plader@sggw.pl

1 Department of Plant Genetics, Breeding and Biotechnology, Institute of Biology, Warsaw University of Life Sciences -

SGGW, 159 Nowoursynowska St, Warsaw, Poland 